\title{
Examining underlying determinants of fertility rates in Zambia: Evidence from the 2007 Zambia Demographic and Health Survey
}

\author{
Mumbi Chola ${ }^{\text {aa }}$, Charles Michelo ${ }^{\text {b }}$ \\ Department of Public Health, University of Zambia, P.O. Box 50110, Lusaka, Zambia \\ email: mumbi24@gmail.com, Cell phone +260968832646
}

\begin{abstract}
Limited data exits on factors influencing fertility in Zambia. This study examined underlying determinants of fertility patterns and levels in Zambia. Data extracted from the 2007 Zambia Demographic and Health Survey was analysed using bivariate and multivariate logistic regression. Of 7I 46 women aged I5-49 years, age group 25-29 years experienced the highest prevalence of births (28.5\%). Married women accounted for $27 \%$ of all births. Women with low education recorded more births $(27 \%)$ than those with higher education $(9.5 \%)(\mathrm{P}<0.00 \mathrm{I})$. Fertility was higher among the poorest $(28 \%)$ compared to the richest $(\mathrm{I} 2 \%)(\mathrm{P}<0.00 \mathrm{I})$. Though not statistically significant, urban areas recorded more births (25\%) than rural areas (I5\%). Education and wealth significantly influence fertility Zambia. Fertility management strategies should consider these factors and their fertility reducing effects. Improving education and wealth status of women can contribute to fertility reduction, particularly rural women. Lower fertility, with reduced mortality and migration, would provide less pressure on distribution of the limited economic resources of the country.
\end{abstract}

Key Words: Underlying determinants, Fertility, Education, Wealth, Zambia

\section{Résumé}

Des données limitées sort sur les facteurs influençant la fécondité en Zambie. Cette étude examine les déterminants sous-jacents de taux de fécondité et les niveaux en Zambie. Les données extraites de I'Enquête Démographique et de Santé de la Zambie de 2007 (NDHS) ont été analysées en utilisant bivariées et régression logistique multivariée. Sur 7/46 femmes âgées de 15-49 ans; groupe d'âge 25-29 ans a connu la plus forte prévalence des naissances (28,5\%). Les femmes mariées représentaient $27 \%$ de toutes les naissances. Les femmes peu scolarisées ont enregistré plus de naissances (27\%) que ceux de l'enseignement supérieur $(9,5 \%)(P<0,00 \mathrm{I})$. En outre, la fécondité était plus élevée chez les plus pauvres $(28 \%)$ par rapport aux plus riches $(I 2 \%)(P<0,00 I)$. Bien que non statistiquement significative, les zones urbaines ont enregistré plus de naissances (25\%) que dans les zones rurales (15\%). Évidemment, l'éducation et la richesse influent considérablement sur la fertilité Zambie. Les stratégies de gestion de la fertilité devrait considération ces deux facteurs et leur fertilité diminuer les effets. Améliorer l'éducation et la richesse statut des femmes peut contribuer à la réduction de la fertilité, particulièrement les femmes rurales. Baisse de la fécondité, couplé avec mortalité et de migration réduite, offrirait moins de pression sur la distribution des ressources économiques limitées du pays.

Mots clés: déterminants sous-jacents, la fertilité, de l'éducation, de richesse, Zambie

\section{INTRODUCTION}

In the last 3 decades, Zambia has continuously reported high fertility rates. Although fertility rates have decreased by one birth over the 27-year period from 7.2 births per woman in the 1980 Census to 6.2 births in the 2007 Zambia Demographic and Health Survey (ZDHS), the total fertility rate still remains high (Central Statistical Office (CSO) et al., 2009 ). Fertility, along with mortality and migration, plays a significant role in driving population growth, and together, these 3 parameters are seen as the principal determinants of changes in population growth.

There are various factors that have an influence on birth and fertility rates and the interaction of these factors ultimately affects fertility rates. The underlying factors that influence births, and in turn fertility, consist mainly of demographic and socio-economic factors such as age, sex, marital status, education and wealth (Reading, 201 I, Weerasinghe and Parr, 2002). Residence is also a factor that is significantly associated with births (Central Statistical Office (CSO) et al., 2009). 
Monitoring fertility is important because increases in fertility rates have far-reaching consequences on quality of life, as it affects things such as the provision of health care, food production, quality of education and resource allocation (Headey, 2009). Therefore, an understanding of determinants of fertility is essential in controlling fertility, a key element in population growth together with mortality and migration.

Although the influence of underlying factors is well documented in other countries, there is limited data on the underlying determinants of fertility in Zambia. This makes it difficult for policy makers to plan make provisions for the population. The aim of this study therefore, was to examine the underlying determinants of fertility rates (specifically age, sex, marital status, education, wealth and religion) in Zambia.

\section{LITERATURE REVIEW AND THEORETICAL FRAMEWORK}

There are various factors that have a bearing or influence on birth rates, and in turn, fertility rates. These factors are termed underlying and proximate determinants (Boermaa and Weir, 2005, Bongaarts and Potter, 1983, Davis and Blake, 1956). The interaction of these factors and births result in either an increase or decrease in births and ultimately fertility rates and this has been shown in various studies (Tey et al., 2012, Lubaale and Kayizzi, 2007,Van Rossem and Meekers, 2007). Underlying determinants include factors that do not directly have an influence on fertility but still have a bearing on fertility outcomes. These include demographic and socio-economic factors such as marital status, education, wealth, residence, age and religion. The effects of education and wealth on fertility are well documented. A study by Karakaya (20I4) found that there was evidence for significant inverse relation between fertility rate and literacy (Karakaya, 20I4). As the level of education increases, the number of births tends to decrease. Analysis by Sabiti (1992) also revealed marked differentials in fertility according to a woman's level of education. Women's education was also found to have a greater influence in restraining fertility than that of the husband (Sabiti, 1992). Where women have higher education, there tends to be lower fertility preferences and more child spacing. This differential in fertility could be attributed to delayed child birth among educated women due to the length of time spent in school. Educated women are more likely to use contraception, have lower fertility preferences and also engage in child spacing due to their understanding of these issues.
With regard to fertility and wealth, Weerasinghe and Parr found that there was a significant negative effect in the logistic regression model of the index of wealth on fertility, indicating that, in Sri Lanka, as accumulated household wealth increases, marital fertility decreases (Weerasinghe and Parr, 2002). They argued that the fertility-reducing effect of higher wealth may be explained in terms of a greater preference among wealthier people for a higher quality as opposed to a higher quantity of children, the rising opportunity costs of parental time, and the reduced reliance on children for support in the old age of the more wealthy parents. Wealthier parents are less likely to have larger numbers of children as a safety net for their old age.

Rural-urban residence has also been associated with fertility. Rural women have reported higher fertility rates than their urban counterparts. This could be attributed to differences in contraceptive prevalence and age at first marriages between urban and rural women (Mekonnen and Worku, 20I I). Women in urban areas tend to delay entry into marriage due to higher education attainment and they are more likely to use modern contraception methods compared to total women.

The conceptual model used in this study was an adaptation of Davis and Blake's analytical framework for the comparative study of the sociology of fertility (Davis and Blake, 1956) and Bongaarts' proximate determinants model (Bongaarts and Potter, 1983). Whereas these models focused on proximate determinants, this study focused on the underlying determinants and how they influence fertility. While fertility is directly and indirectly influenced by various factors which can be termed proximate and distal (underlying) determinants, this model looks at factors that indirectly influence fertility. These include demographic and socio-economic factors that play a role in influencing the number of births and thus fertility.

\section{DATA AND METHODS}

This was a cross sectional quantitative study analysing data from the 2007 Zambia Demographic and Health Survey (ZDHS). The ZDHS is a nationally representative survey of Zambian households with a representative sample of 8,000 households. All women aged 15-49 years and men 15-59 years who were either permanent residents of the households in the sample or visitors present in the household on the night before the survey were eligible to be interviewed. Fertility data was collected from all women aged 15-49 years. Data collected included levels, patterns, and trends in both current and cumulative fertility, the length of birth intervals, and the age at which women begin childbearing. Family 
planning data was also collected on a number of aspects of contraception including knowledge of specific contraceptive methods, attitudes and behaviour regarding contraceptive use, sources and costs of methods. The focus of this study was on women who were sexually active because these women had the greatest risk of exposure to pregnancy (Central Statistical Office (CSO) et al. 2009).

The ZDHS is a stratified sample selected in two stages from the 2010 Census of Population and Housing frame. Stratification was achieved by separating every province into urban and rural areas. Therefore, the nine provinces were stratified into 18 sampling strata. Samples were selected independently in every stratum by a two-stage selection.

The outcome variable was the number of live births recorded in the year preceding the survey, that is, whether the woman gave birth in the year before the research was undertaken. This was a dichotomous variable with those who gave birth coded as 0 and those who did not give birth coded as I. The explanatory variables included age, marital status, education, wealth and religion. These variables were obtained from the ZDHS data set and were retained in their original format.

Bivariate analyses were performed to determine the relationship between the dependent variable, live births, and each of the explanatory variables. These were tested using chi square and were considered significant at $P<0.05$. Logistic regression analysis was used to determine which underlying determinants are predominant in influencing fertility. All the explanatory variables were fitted into the model and were considered significant at $95 \%$ confidence interval. Furthermore, backward stepwise regression was applied fitting all the factors.

\section{RESULTS}

\section{Population Description}

The sample consisted on 7,I46 females who responded to the question on whether they had given birth in the year preceding the study. Majority (22\%) of the respondents were aged 15-19 years. The mean age of the respondents was 27.9 years and the median age was 26 years. Forty-four percent of the respondents resided in rural areas while about $56 \%$ resided in urban areas. Majority $(60 \%)$ of the respondents were married and $27.2 \%$ were never married. Approximately 10\% of the respondents had no education while $53 \%$ had attained at least primary education. About $31 \%$ had secondary education and $5 \%$ had tertiary education. Education system in Zambia has three levels namely primary level, secondary level and tertiary level. Results reported refer to the highest level of education attained by the respondent. This distribution of the population with regard to the variables under study is depicted in Table I.

With regard to the wealth, the majority of the respondents (47\%) were in the rich category with the poor constituting $33 \%$. Twenty percent of the respondents were in the middle category on the wealth index. The largest religious group were the Protestants with $79.1 \%$ and Catholics constituting $19.1 \%$. Muslims were the smallest group with $0.4 \%$ of the respondents.

Table I: Socio-demographic characteristics

\begin{tabular}{lll} 
Characteristic & $\mathbf{n}=7 \mid 46$ & $\mathbf{n}(\%)$ \\
\hline Births & Yes & $1,46 \mid(20 \%)$ \\
& No & $5,685(80 \%)$ \\
\hline Age (Grouped) & $15-19$ & $1,598(22 \%)$ \\
& $20-24$ & $1,407(20 \%)$ \\
& $25-29$ & $1,374(19 \%)$ \\
& $30-34$ & $1,042(15 \%)$ \\
Mean age & $35-39$ & $732(10 \%)$ \\
Median age & $40-44$ & $533(7 \%)$ \\
\hline Marital Status & $45-49$ & $462(6 \%)$ \\
& & 27.9 \\
& & 26.0 \\
\hline & Never Married & $1,941(27 \%)$ \\
& Married & $4,264(60)$ \\
& Living Together & $52(1 \%)$ \\
& Widowed & $312(4 \%)$
\end{tabular}




\begin{tabular}{lll}
\hline \multicolumn{2}{l}{ Table I: Socio-demographic characteristics } \\
Characteristic & $\mathbf{n = 7 I 4 6}$ & $\mathbf{n}(\%)$ \\
\hline & Divorced & $422(6 \%)$ \\
& Not Living Together & $155(2 \%)$ \\
\hline Residence & Urban & $3,178(44 \%)$ \\
& Rural & $3,968(56 \%)$ \\
\hline Education (Highest level) & No education & $741(10 \%)$ \\
& Primary & $3805(53 \%)$ \\
& Secondary & $12242(31 \%)$ \\
& Higher & $358(5 \%)$ \\
\hline Wealth Index & Poor & $1,131(16 \%)$ \\
& Poorer & $1,245(17 \%)$ \\
& Middle & $1,409(20 \%)$ \\
& Rich & $1,733(24 \%)$ \\
& Richest & $1,628(23 \%)$ \\
\hline Religion & Catholic & $1,368(19 \%)$ \\
& Protestant & $5,652(79 \%)$ \\
& Muslim & $26(0 \%)$ \\
& Other & $90(1 \%)$ \\
& Non Response & $10(0 \%)$ \\
\hline
\end{tabular}

$\alpha$ - denoted No response

\section{Fertility patterns and differentials}

Bivariate analysis of fertility in relation to the determinants of interest such as age, marital status, education and wealth showed varying patterns. Table 2 shows the results of chi square tests. The table shows which independent variables were significant and which ones were not at $95 \%$ confidence interval. Results show that age, marital status, residence, education and wealth were all significant $(p=0.00)$ at $95 \%$ confidence interval. Only religion was not significant with $\mathrm{p}=0.63$.

The highest number of births (29\%) were recorded among respondents aged 25-29 years followed by those aged 20-24 years who recorded $28 \%$. the age group $45-49$ reported the least births with $3 \%$. This is depicted in figure I below. This pattern is consistent with the reproductive life cycle of women. With regard to rural-urban residence, more births were recorded in rural areas compared to urban areas. About 10\% more births were reported in urban $(25 \%)$ areas than in urban areas (I5\%). Rural-urban differentials showed that there were more births among women aged below 25-29 in urban areas compared to rural areas while the reverse was the case for women above this age group. This is also shown in figure I.

Table 2: Cross tabulation of births and all background characteristics

$\begin{array}{ll}\mathrm{n}=7 \mid 46 & \mathrm{P}- \\ & \text { Value } \\ & \chi 2\end{array}$

\section{Characteristic}

Births (year preceding the Survey)

\begin{tabular}{lllll}
\hline Age (Grouped) & I5-19 & $202(\mid 2.6)$ & $1,396(87.4)$ & 0.00 \\
& $20-24$ & $389(27.7)$ & $1,06 \mid(72.3)$ & \\
$25-29$ & $392(28.5)$ & $982(7 \mid .5)$ & \\
$30-34$ & $265(25.4)$ & $777(74.6)$ & \\
$35-39$ & $148(20.2)$ & $584(79.8)$ & \\
& $40-44$ & $50(9.4)$ & $483(90.6)$ & \\
& $45-49$ & $15(3.3)$ & $447(96.8)$ & \\
\hline Marital Status & Married & $\mathrm{I}, 19 \mid(27.9)$ & $3,073(72.1)$ & 0.00 \\
& Not Living Together & $3 \mid(20.0)$ & $124(80.0)$ &
\end{tabular}


Table 2: Cross tabulation of births and all background characteristics

\begin{tabular}{|c|c|c|c|c|}
\hline \multirow[t]{5}{*}{ Characteristic } & & & & \multirow[t]{2}{*}{$x 2$} \\
\hline & Living Together & $10(19.2)$ & $42(80.8)$ & \\
\hline & Divorced & $48(\mid I .4)$ & $374(88.6)$ & \\
\hline & Never Married & $160(8.2)$ & I,78I (9I.8) & \\
\hline & Widowed & $21(6.7)$ & $291(93.3)$ & \\
\hline \multirow[t]{2}{*}{ Residence } & Urban & $479(15.1)$ & $2,699(84.9)$ & 0.00 \\
\hline & Rural & $982(24.8)$ & $2,986(75.3)$ & \\
\hline \multirow[t]{4}{*}{ Education (Highest level) } & No Education & $20 I(27.1)$ & $540(72.9)$ & 0.00 \\
\hline & Primary & $878(23.1)$ & $2,927(76.9)$ & \\
\hline & Secondary & $348(15.5)$ & I,894 (84.5) & \\
\hline & Higher & $34(9.5)$ & $324(90.5)$ & \\
\hline \multirow[t]{5}{*}{ Wealth Index } & Poorest & $313(27.7)$ & $818(72.3)$ & 0.00 \\
\hline & Poorer & $319(25.6)$ & $926(74.4)$ & \\
\hline & Middle & $333(23.6)$ & $\mathrm{I}, 076(76.4)$ & \\
\hline & Richer & $308(17.8)$ & $\mathrm{I}, 425(82.2)$ & \\
\hline & Richest & $108(11.6)$ & $\mathrm{I}, 440(88.5)$ & \\
\hline \multirow[t]{5}{*}{ Religion } & Catholic & $269(19.7)$ & $\mathrm{I}, 099(80.3)$ & 0.63 \\
\hline & Protestant & $\mathrm{I}, 16 \mathrm{I}(20.5)$ & $4,491(79.5)$ & \\
\hline & Muslim & $5(119.2$ & $21(80.8)$ & \\
\hline & Other & $23(25.6)$ & $67(74.4)$ & \\
\hline & Missing & $3(30.0)$ & $7(70.0)$ & \\
\hline
\end{tabular}

x2 - Pearson's Chi square

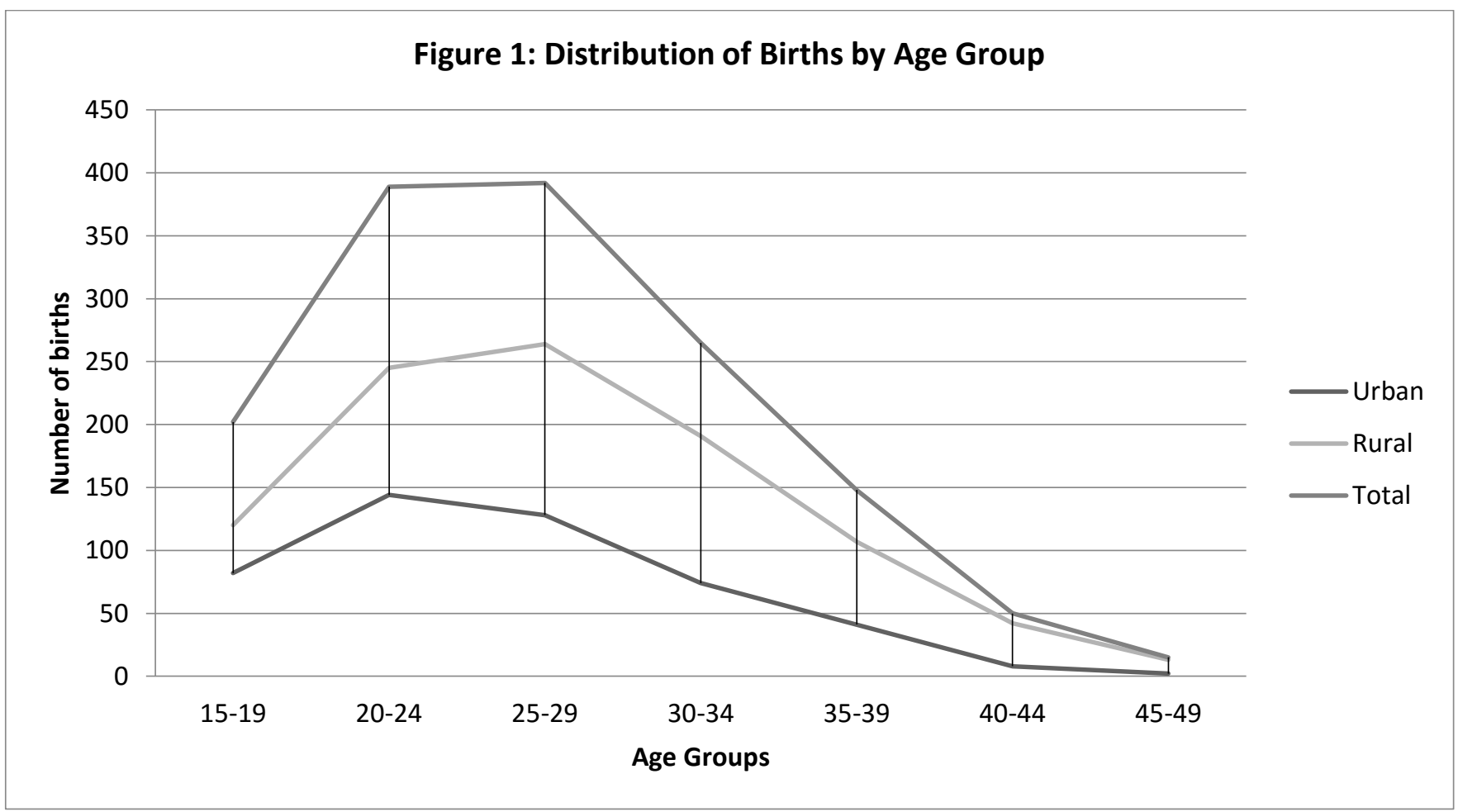

Distribution of births by current marital status was such that the majority of births were recorded among married women. About $28 \%$ of the married respondents reported having given birth in the year preceding the survey. Slightly more than one fifth of the births were recorded among those not living together with their partner. About 19\% of the 
women reported having given birth while the never married group reported $8.2 \%$.

As shown in table I, results show that there was an inverse relationship between education level and births. As education level increased, the percentage of births recorded reduced. Those with no education recorded the most births at $27.1 \%$ with those in primary recording $23.1 \%$. Those who had attained secondary education recorded $15.5 \%$ where as those with higher education recorded $9.5 \%$. As the level of education increased, the likelihood of experiencing child birth reduced. Results from the logistic regression analysis (table 3) show that in comparison to those with no education, those who attain primary education have $17 \%$ less chance of experiencing child birth though there's no significant difference (OR $0.83,0.68-1.0195 \% \mathrm{Cl}$ ). This reduces further among those with secondary education to $23 \%$ while those with higher education $41 \%$ were less likely to experience child birth, significant at $95 \%$ (OR 0.77, $0.61-.96 \mathrm{Cl}$ and $0.59,0.37-0.9 \mathrm{I} \mathrm{Cl}$ respectively). There was, however, no significant difference between births and level of education in both rural and urban residences. This implied that residence had no influence on the relationship between births and education level.
A similar inverse relationship was observed with regards to wealth. As the wealth index increased, births reduced with the poorest recording $27.7 \%$ and the richest less than half this figure at $11.6 \%$. As depicted in table 3 , differences between the poorest, poorer and middle wealth indexes were not statistically significant at $95 \%($ OR $0.92,0.76-1.12 \mathrm{Cl}$ and $\mathrm{OR} 0.82,0.68-\mathrm{I} .00 \mathrm{Cl}$ respectively). With regards to residence, statistically significant differences were observed in rural areas with the richest having $50 \%$ less chance of experiencing childbirth compared to the poorest (OR 0.50. 0.25$0.97 \mathrm{Cl}$ ). Logistic regression analysis of fertility and residence, while controlling for age, marital status, education and religion, however, showed that there was no significant difference in terms of fertility between urban and rural areas.

Table 4 shows results from the stepwise regression to determine the predictors of births among women aged 15-49 years in Zambia. Results show that wealth, education, age, marital status and residence are the underlying predictors of fertility. While wealth, age and education (highest level) were strongly significant $(p=0.000)$, marital status and residence were borderline significant as shown by the confidence intervals (see table 4).

\begin{tabular}{llll}
\hline \multicolumn{4}{l}{ Table 3: Logistic Regression with Adjusted Odds Ratios for all underlying determinants } \\
\hline $\mathbf{n = 7 | 4 6}$ & TOTAL & RURAL & URBAN \\
\hline Characteristic & aOR $(95 \% \mathrm{Cl})$ & aOR $(95 \% \mathrm{Cl})$ & aOR $(95 \% \mathrm{Cl})$ \\
\hline $\mathrm{I} 5-19$ & Ref & & \\
$20-24$ & $\mathrm{I} .22(0.97-\mathrm{I} .53)$ & $\mathrm{I} .38(\mathrm{I} .03-\mathrm{I} .85)$ & $\mathrm{I} .02(0.7 \mathrm{I}-\mathrm{I} .46)$ \\
$25-29$ & $\mathrm{I} .09(0.86-\mathrm{I} .38)$ & $\mathrm{I} .40(\mathrm{I} .04-\mathrm{I} .89)$ & $0.7 \mathrm{I}(0.48-\mathrm{I} .04)$ \\
$30-34$ & $0.86(0.67-\mathrm{I} .1 \mathrm{I}$ & $\mathrm{I} .10(0.80-\mathrm{I} .5 \mathrm{I})$ & $0.55(0.36-0.84)$ \\
$35-39$ & $0.63(0.48-0.83)$ & $0.78(0.55-1.10)$ & $0.43(0.27-0.69)$ \\
$40-44$ & $0.26(0.18-0.37)$ & $0.38(0.25-0.58)$ & $0.10(0.04-0.2 \mathrm{I})$ \\
$45-49$ & $0.08(0.05-0.14$ & $0.12(0.07-0.23)$ & $0.02(0.01-0.1 \mathrm{I})$ \\
\hline
\end{tabular}

Marital Status

Never Married

Married

Ref

Living together

4.72 (3.77-5.9I)

$3.66(2.7 \mid-4.95)$

$6.98(4.93-9.88)$

Widowed

$3.43(1.66-7.09)$

$3.48(0.87-13.89)$

$3.93(1.64-9.40)$

Divorced

$1.47(0.88-2.43)$

I. $37(0.69-2.7 \mathrm{I})$

I.84 (0.85-3.98)

Not living together

$1.65(1.13-2.40)$

$1.47(0.93-2.34)$

$1.73(0.87-3.43)$

$3.08(1.95-4.87)$

$2.06(1.12-3.80)$

$5.62(2.80-11.30)$

\section{Residence}

Urban Ref

Rural

I.04 (0.85-I.26)

Education (Highest Level)

No education

Primary

Secondary

Ref

Higher

$\begin{array}{ll}0.83(0.69-I .0 I) & 0.82(0.67-I .0 I) \\ 0.77(0.6 I-0.96) & 0.78(0.59-I .04) \\ 0.59(0.37-0.9 I) & 0.28(0.06-I .28)\end{array}$

$1.02(0.6 \mathrm{I}-\mathrm{I} .72)$

$0.87(0.5 \mathrm{I}-\mathrm{I} .48)$

$0.78(0.40-1.49)$ 
Table 3: Logistic Regression with Adjusted Odds Ratios for all underlying determinants

\begin{tabular}{llcl}
\hline $\mathbf{n}=7 \mid 46$ & TOTAL & \multicolumn{1}{c}{ RURAL } & URBAN \\
\hline Wealth & & & \\
Poor & Ref & & \\
Poorer & $0.92(0.76-1.12)$ & $0.92(0.76-1.12)$ & $2.30(0.92-5.76)$ \\
Middle & $0.82(0.68-1.00)$ & $0.81(0.66-0.99)$ & $1.66(1.17-2.37)$ \\
Richer & $0.67(0.52-0.85)$ & $0.74(0.55-0.99)$ & $1.17(0.92-1.49)$ \\
Richest $^{\alpha}$ & $0.52(0.38-0.70)$ & $0.50(0.25-0.97)$ & (omitted) \\
\hline Religion & & & \\
Catholic & Ref & & \\
Protestant & $0.94(0.81-1.10)$ & $0.92(0.75-1.11)$ & $0.98(0.76-1.28)$ \\
Muslim & $0.98(0.35-2.77)$ & $2.07(0.54-7.87)$ & $0.30(0.04-2.43)$ \\
Other & $1.17(0.69-1.99)$ & $1.22(0.69-2.16)$ & $0.74(0.16-3.52)$ \\
\hline
\end{tabular}

$\alpha$ - Urban figures omitted in the regression analysis because of co-linearity

Table 4: Forward stepwise regression model fitting all underlying determinants

\begin{tabular}{lllll}
\hline & Odds Ratio & $\mathrm{P}>\mathrm{z}$ & {$[95 \%$ Conf. } & Interval] \\
\hline Wealth & 0.85 & 0.000 & 0.80 & 0.91 \\
Age & 0.88 & 0.000 & 0.85 & 0.91 \\
Education ( Highest Level) & 0.77 & 0.000 & 0.70 & 0.85 \\
Marital Status & 1.06 & 0.044 & 1.00 & 1.12 \\
Residence & 1.18 & 0.065 & 0.99 & 1.42 \\
\hline
\end{tabular}

\section{DISCUSSION}

The main results of this research were that there was a statistically significant negative relationship between fertility and wealth and education. Fertility was lower among women with higher education as well as with women higher on the wealth index. This is consistent with findings in other studies conducted in Africa (Mekonnen and Worku, 20II, Ushie et al., 20II, Adebowale and Palamuleni, 2014). Adebowale and Palamuleni found that among married women in Nigeria, the completed fertility of women who had no formal education was higher than those with higher level of education. We found that fertility was almost twice as high among uneducated women in comparison to women with higher education. The fertility reducing effects of education may be due to delayed pregnancy and marriage among the educated women because they spend more time in school. Educated women tend to postpone marriage (Adhikari, 2010) which seems to be a driver of fertility as the highest fertility rates are recorded among married women. Majority of births are reported among married women. Furthermore, educated women are more likely to use modern contraception methods than women with no education and thus may prefer to limit their family sizes to smaller numbers than those with little or no education. As reported in the 2007 ZDHS, contraception increased with education attainment which may contribute to lower fertility among educated women (Central Statistical Office (CSO) et al., 2009 ). As explained by Bongaarts (2010), as education rises, fertility is lower at a given level of contraceptive use, contraceptive use is higher at a given level of demand, and demand is higher at a desired level of family size. The most plausible explanation for these shifting relationships are that educated women marry later and less often, use contraception more effectively, have more knowledge about and access to contraception, have higher autonomy in reproductive decision making, and are more motivated to implement demand because of the higher opportunity costs of unintended childbearing (Bongaarts, 20I0). Educated women also tend to leave longer intervals between two successive births. (Adebowale and Palamuleni, 20I4, Setty-Venugopal and U.D., 2002.).

An inverse relationship was also observed between wealth and fertility. Fertility was almost twice as high among poor women as the richest women. This is also consistent with findings from other studies (Adhikari, 2010, Weerasinghe and Parr, 2002, lara et al., 2013, Adebowale and Palamuleni, 20I4). A study in Malawi revealed that the mean children ever born and adjusted Total Fertility Rate (TFR) were higher among women in the poorest than 
those in the richest wealth quintile. Also, across all the 5-year age groups, fertility rate was consistently higher among women in poorest wealth quintile than those in the richest wealth quintile (Adebowale et al., 2014). It was also found that higher birth intervals and lower completed fertility were reported among the urban women and richest wealth quintiles (Adebowale and Palamuleni, 20I4). This inverse relationship between fertility and wealth may be attributed to the child preferences and access to and usage of contraception among the richer women (Weerasinghe and Parr, 2002). Richer women tend to prefer smaller numbers of children compared to poorer women. A qualitative study in Nigeria found that while people desire high number of children, they have been revising the number of children they are having downward due to the 'supposed' economic hardship in the country, which has put a constraint on giving quality education, training and care to a large number of children (lbisomi, 20l0). Women in higher wealth quintiles are also more likely to use contraception and in cases where there may be financial implications, they may be able to afford the cost of contraception. Furthermore, they are more likely to have information on and access to contraception and quality of health care which may not be available to those in lower wealth quintiles. In a study on the impact of wealth and female autonomy on fertility decisions in Nepal, Gudbrandsen argues that one explanation of why households with higher wealth tend to have fewer children is that they can afford to invest in their children and therefore prefer to have few children with high quality and education, rather than many children. (Gudbrundsen, 20I0).

Disparities in fertility rates in terms of residence are similar to those recorded in other studies. Fertility rates were significantly higher in rural areas than in urban areas although analysis of fertility and residence while controlling for age, marital status, education, wealth and religion showed that there was no significant difference between urban and rural residence. This is similar to finding in other studies (Ahmad, 1985, Weerasinghe and Parr, 2002, Decker and Constantine, 20I I). In Ethiopia, it was found that rural women were 2.66 times more likely to practice birth interval length less than 3 years as compared to their urban counterparts and have 4 months longer median birth interval length than rural women. Better social services and access to information, education and employment opportunities could have brought about variation by residence (Yohannes et al., 20l I). Furthermore, contraceptive use is significantly higher in urban areas than in rural areas. Reasons for this disparity were explained in a study done in Angola where qualitative interviews among health professionals who mentioned rural living, young age, cultural beliefs, and power imbalances as reasons for not using contraception. Women in rural areas tend to marry early and have less decision making power with regard to the number of children especially in cases where they marry much older men. Furthermore, internally displaced women often described difficulty paying for services, lack of nearby services, and limited knowledge of methods as barriers to use (Decker and Constantine, 20II). These reasons for non-use of contraception may contribute to higher fertility in rural areas.

These disparities could be also due to the fertility reducing effects of factors such as wealth and education being stronger in urban areas than in rural areas (Hollos and Larsen, 1992). As earlier alluded to, issues of disparities in access to and use of contraception, fertility preferences, cultural beliefs, economic factors, age at first marriage and birth among others contribute to fertility differentials in urban and rural areas.

\section{LIMITATIONS}

The study had some limitations. The research focused on the 2007 ZDHS because at the time the research was being done, this was the most recent version of the ZDHS. This may have implications in that similar research on more recent data may yield different results from those presented above.

Being a cross sectional study by design, it is not possible to determine causality. Only the presence or absence of a relationship between the dependent variable and explanatory variables can be determined.

Despite these limitations, the study was based on the ZDHS which is a nationally representative study and as a result, the findings can be generalised to the general population of Zambia.

\section{CONCLUSION}

Zambia has been characterised by high fertility rates. This has been a common phenomenon over the years. These high fertility rates, coupled with the effects of mortality and migration, have resulted in rapid population growth which has put a strain on the resources of the country, both natural and socioeconomic. As such it was essential to get an understanding of the underlying determinants of fertility, beyond just the proximate determinants, to provide an understanding of these determinants and to also help shape policies aimed at managing fertility and population growth. Through this study, it was determined that fertility rates are highest among younger women and married women. It was also established that there exists an inverse relationship between fertility and education as well as fertility and wealth. Rural-urban disparities in fertility were also noted. 
It is important, therefore, that policies and projects aimed at improving the education and economic status of women be promoted. Government programmes centred on promotion of girl child education and economic empowerment of women should be encouraged and strengthened to ensure sustainability. Such policies particularly among women in rural areas may contribute significantly to reduction in fertility in Zambia. This can contribute to reduction in population growth. This would benefit the population in terms of distribution of the limited economic resources. Additionally, advocating for child spacing and reduction in number of children may benefit women of childbearing age and underfive children by improving their health and survival chances thus contributing to reduction in maternal mortality.

\section{ACKNOWLEDGEMENTS}

We acknowledge the support provided by the Research Support Centre at the University of Zambia, School of Medicine (UNZA-SOM) through the Southern African Consortium for Research Excellence (SACORE), which is part of the African Institutions Initiative Grant of the Wellcome Trust (company no. 27/1000), a charity (no. 210183) registered in England; The National Institutes of Health $(\mathrm{NIH})$ through the Medical Education Partnership Initiative (MEPI) programmatic award No. IR24TW008873 entitled "Expanding Innovative Multidisciplinary Medical Education in Zambia" at UNZA-SOM; and the Norwegian Agency for Development Cooperation (NORAD)'s Programme for Master Studies (NOMA), Project number NOMA-20 I0/ $284 \mid$ which is a tripartite cooperation between the University of Bergen, Norway, College of Medicine in Malawi and the Department of Public Health, University of Zambia. We also acknowledge the various contributions made by the following people for this work: The members of the UNZASOM SACORE Steering Committee (Dr Margret Maimbolwa, Dr Paul Kelly, Dr Helen Ayles, \& Dr Charles Michelo) and Mr Maxward Katubulushi, Mrs Choolwe Nkwemu Jacobs, Ms Mutanti Simonda and Ms Mulemwa Mwangala arranging analytical support. We would also like to thank Ms Nsipa Sichone for the French translation of the abstract.

\section{AUTHOR GUARANTEE}

All named authors have contributed sufficiently to the work submitted and the content of the manuscript has never been previously published

\section{REFERENCES}

ADEBOWALE, S. A., ADEDINI, S. A., IBISOM, L. D. \& PALAMULENI, M. E. 20I4. Differential effect of wealth quintile on modern contraceptive use and fertility: evidence from Malawian women. BMC Women's Health, I4.

ADEBOWALE, S. A. \& PALAMULENI, M. E. 2014. Childbearing dynamics among married women of reproductive age in Nigeria: re-affirming the role of education. African Population Studies Vol 27, 2 Supp.

ADHIKARI, R. 20I0. Demographic, socioeconomic, and cultural factors affecting fertility differentials in Nepal. BMC Pregnancy and Childbirth, 10.

AHMAD, S. 1985. Rural-urban differentials in marital fertility in four Muslim populations. Journal of Biosocial Science, 17, pP 157-166. doi:10.1017/S00219320000156/3.

BOERMAA, J. T. \& WEIR, S. S. 2005. Integrating Demographic and Epidemiological Approaches to Research on HIV/AIDS: The ProximateDeterminants Framework. The Journal of Infectious Diseases, I9I(Suppl I).

BONGAARTS, J. 2010. The causes of educational differences in fertility in Sub-Saharan Africa. Vienna Yearbook of Population Research, Vol. 8, Pp. 3I-50

BONGAARTS, J. \& POTTER, J. E. 1983. Fertility, Biology and Behavior. New York: Academic Press. CENTRAL STATISTICAL OFFICE (CSO), MINISTRY OF HEALTH $(\mathrm{MOH})$, TROPICAL DISEASES RESEARCH CENTRE (TDRC), UNIVERSITY OF ZAMBIA \& INC., M. I. 2009 Zambia Demographic and Health Survey 2007. Calverton, Maryland, USA CSO and Macro International Inc.

DAVIS, K. \& BLAKE, J. 1956. Social structure and fertility: an analytical framework. Econ Dev Cult Change, 4:2II-35.

DECKER, M. \& CONSTANTINE, N. A. 2011. Factors associated with contraceptive use in Angola. African Journal of Reproductive Health Vol I5 67-77.

GUDBRUNDSEN, N. H. 2010. The Impact of Wealth and Female Autonomy on Fertility Decisions in Nepal: An Econometric Analysis Bergen: 64 p: Chr. Michelsen Institute Working Paper

HEADEY, D. D., HODGE, A 2009. The Effect of Population Growth on Economic Growth: A Meta-Regression Analysis of the Macroeconomic Literature. Population and Development Review, 35, 22I-248. doi: $\quad 10.1 \mathrm{II} / \mathrm{j}$. I7284457.2009.00274.x.

HOLLOS, M. \& LARSEN, U. 1992. Fertility differentials among the ljo in southern Nigeria: does urban residence make a difference? Soc Sci Med., 35, II99-2I0. 
IBISOMI, L. D. G. 20I0. Fertility Transition in Nigeria: Exploring the Role of Desired Number of Children. African Population Studies Vol. 23.

JARA, D., DEJENE, T. \& TAHA, M. 2013. Determinants of High Fertility Status Among Married Women in Gilgel Gibe Field Research Center of Jimma University, Oromia, Ethiopia: A Case Control Study. Public Health Research, 3, 917.

KARAKAYA, E. 20I4. Socioeconomic Determinants on Fertility Rate at an Aggregate Level: A Linear Regression Model for Turkish Provinces. Public Knowledge Journal, 6.

LUBAALE, M. Y. A. \& KAYIZZI, J. B. 2007. Using the Bongaarts model in explaining fertility decline in Urban areas of Uganda. Fifth African Population Conference. Arusha.

MEKONNEN, W. \& WORKU, A. $201 \mathrm{l}$. Determinants of fertility in rural Ethiopia: the case of Butajira Demographic Surveillance System (DSS). . BMC Public Health, I I:.

READING, B. F. 20II. Education Leads to Lower Fertility and Increased Prosperity [Online]. Available: $\quad$ http://www.earthpolicy.org/data_highlights/20 I //highlights I 3 [Accessed 17th May 2013].
SABITI, K. 1992. Socio-economic factors affecting fertility in Kenya. South African Journal of Sociology, Volume 23, .

SETTY-VENUGOPAL, V. \& U.D., U. 2002. . Birth Spacing: Three to five saves lives. Population Reports. Baltimore: John Hopkins Bloomerg School of Public Health.

TEY, N. P., NG, S. T. \& YEW, S. Y. 20I2. Proximate determinants of fertility in peninsular Malaysia. Asia Pac J Public Health, 24, 495-505.

USHIE, M. A., AGBA, A. M. O., OLUMODEJI, E. O. \& ATTAH, F. 20II. Socio-cultural and economic determinants of fertility differentialsin rural and urban Cross River State, Nigeria. Journal of Geography and Regional Planning, 4(7), 383-39I.

VAN ROSSEM, R. \& MEEKERS, D. 2007. The reach and impact of social marketing and reproductive health communication campaigns in Zambia. BMC Public Health 7:352.

WEERASINGHE, D. P. \& PARR, N. J. 2002. Effect of Wealth on Marital Fertility in Sri Lanka. J Health Popul Nutr, 20, II 2-I 19.

YOHANNES, S., WONDAFRASH, M., ABERA, M. \& GIRMA, E. 20II. Duration and determinants of birth interval among women of child bearing age in Southern Ethiopia. BMC Pregnancy and Childbirth, II. 